\title{
Polymerizability of Isomerically Trimethylsilyl Substituted Styrenes
}

\author{
Yusuke KaWAKAMI* and Ruben Walter CAIRO \\ Department of Synthetic Chemistry, School of Engineering, \\ Nagoya University, Chikusa, Nagoya 464, Japan
}

(Received October 8, 1990)

\begin{abstract}
Polymerizability of isomerically trimethylsilyl and pentamethyldisiloxanyl substituted styrenes was studied. In the polymerization, $o$-substituted isomers gave low molecular weight polymer in low yield. Chain transfer constant to the $o$-trimethylsilyl substituted monomer was estimated to be quite large as a styrene type monomer. In NMR spectrum, $\alpha$-vinyl proton of $o$-isomers shifted to the lower field compared with that of $m$ - or $p$-isomers, and $9 \%$ of nuclear Overhauser enhancement (NOE) was observed for $\alpha$-vinyl proton of $o$-trimethylsilylstyrene under irradiation on silylmethyl proton. The characteristic polymerization behavior of the $o$-isomers is discussed.
\end{abstract}

KEY WORDS Trimethylsilyl Group / Steric Effect / Radical Polymerization / Anionic Polymerization / $d$-Orbital / Nuclear Overhauser Enhancement / Reaction Mechanism /

As reported in previous papers, ${ }^{1-5)}$ polymers from oligodimethylsiloxanyl substituted styrenes are good materials for selective oxygen separation from air. The high permeability of gas was attributed to the lowered glass transition temperature of the polymer and high diffusivity of gas brought about by highly mobile oligodimethylsiloxanyl side chains even in the solid state.

Trimethylsilyl substituted polystyrene, which does not have siloxane linkage, also exhibited enhanced permeation of gases compared with polystyrene. However, the reason for the high permeability seems different from that for the oligodimethylsiloxanyl substituted polymers. It will be interesting to elucidate the role of bulky groups such as trimethylsilyl group on the polymerizability of monomers and the gas permeation behavior.

In the synthesis of polymers of isomerically trimethylsilyl substituted styrenes along with the direction of our study, we noticed an interesting effect of the $o$-trimethylsilyl group on proton and carbon NMR chemical shifts of the vinyl proton, and also on the polymerizability of the monomer. In this article, we would like to report mainly the study of the effects of the isomerically substituted trimethylsilyl group on the phenyl ring of styrene on the chemical shifts in NMR spectra and to give possible explanation on the low reactivity of the $o$-substituted monomer in polymerization.

\section{EXPERIMENTAL}

\section{General}

IR, ${ }^{1} \mathrm{H}$, and ${ }^{13} \mathrm{C}$ NMR spectra were recorded on a JASCO FT-IR spectrometer model FT7000, and on a Varian NMR spectrometer model Gemini $200\left(200 \mathrm{MHz}\right.$ for ${ }^{1} \mathrm{H}, 50 \mathrm{MHz}$ for ${ }^{13} \mathrm{C}$ ). Chemical shifts are given as $\delta$ in ppm from tetramethylsilane as an internal standard. Nuclear Overhauser enhancement (NOE) analysis was made on a Varian $500 \mathrm{MHz}{ }^{1} \mathrm{H}$ NMR spectrometer model VXR-500. Monomers were purified by column chromatography (Wako Silica gel 60) with hexane as the eluent. 


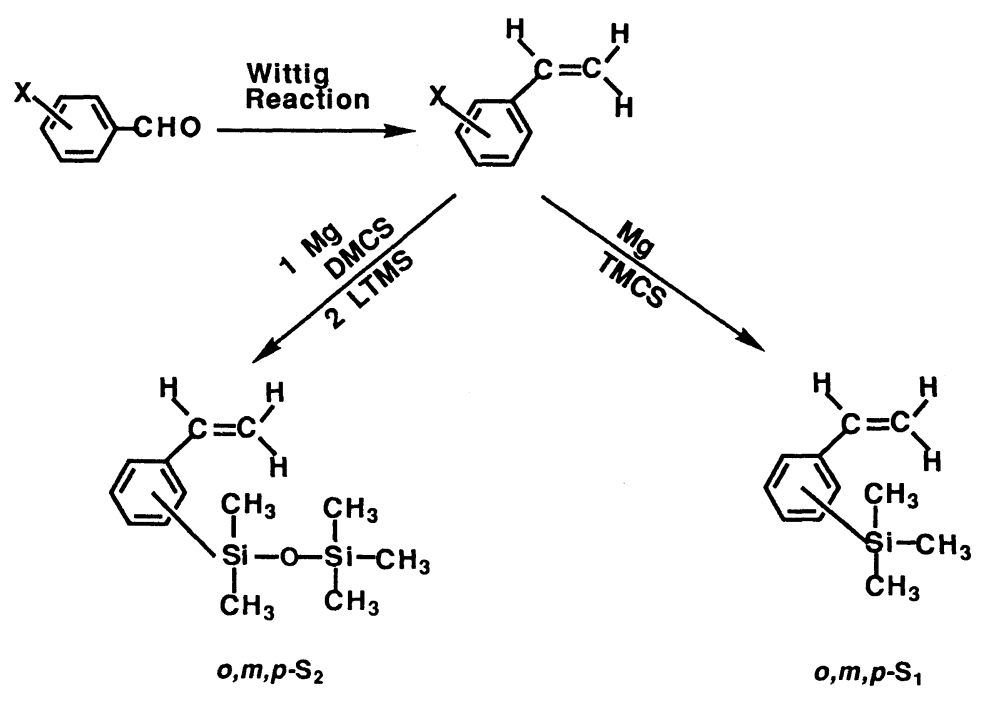

Scheme 1. Synthetic route to $o$-substituted styrenes.

Number-average molecular weights of polymers were determined by a Corona vapor phase osmometer model 114. Gel permeation chromatograms were recorded on a JASCO high pressure liquid chromatograph model 880 . Thermal analysis of polymers were made on a SEIKO thermal analysis system model SSC5000 equipped with DSC 100.

\section{Synthesis of Monomers}

Halogenostyrenes were synthesized from halogenobenzaldehyde via Wittig reaction.

$o-, m-, p$-Trimethylsilylstyrenes $\left(o-, m-, p-\mathrm{S}_{1}\right)$ were synthesized via Grignard reaction from $o-, m-, p$-halogenostyrene in the presence of trimethylcholorosilane (TMCS) according to Scheme 1.

Reaction with dimethyldichlorosilane (DMCS) first and then the coupling of remaining chlorosilane group with lithium trimethylsilanolate (LTMS) gave $o-, m-, p-$ pentamethyldisiloxanylstyrenes $\left(o-, m-, p-\mathrm{S}_{2}\right)$.

In NMR assignment, vinyl protons of the monomers, $\mathrm{Ha}, \mathrm{Hb}$, and $\mathrm{Hc}$ and number of carbon atoms in the aromatic ring are as follows.

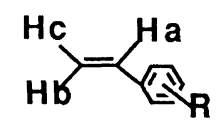<smiles>CCc1ccccc1[Si](C)C</smiles>

$o$-Trimethylsilylstyrene $\left(o-S_{1}\right)$

To a solution of triphenylphosphine $(24.50 \mathrm{~g}$, $93.41 \mathrm{mmol}$ ) in benzene ( $90 \mathrm{ml}), 5 \mathrm{~N}$ aq. sodium hydroxide solution $(226 \mathrm{ml}), o$-bromobenzaldehyde $(8.20 \mathrm{~g}, 44.30 \mathrm{mmol})$ and methyl iodide $(12.58 \mathrm{~g}, 88.62 \mathrm{mmol})$ were added, and the reaction mixture was stirred vigorously for $24 \mathrm{~h}$ at $40^{\circ} \mathrm{C}$. After the reaction, the organic layer was separated, followed by repeated extraction with $1 N$ aq. sodium hydroxide solution to remove triphenylphosphine oxide as much as possible. The benzene solution was dried over magnesium sulfate. A small amount of hexane was added to produce further precipitation of triphenylphosphine oxide. After benzene was evaporated, the product, $o$-bromostyrene ${ }^{6}$ was obtained in $75 \%$ yield and purified by column chromatography $(R f=0.6)$.

Carefully dried $\mathrm{Mg}$ turnings $(1.06 \mathrm{~g}, 43.60$ mmol) was activated by mechanical agitation without solvent under nitrogen atmosphere in 
a three-necked flask. Dry tetrahydrofuran (THF) was added to cover $\mathrm{Mg}$, and few drops of 1,2-dibromoethane were added to activate $\mathrm{Mg}$. Then, trimethylchlorosilane $(3.56 \mathrm{~g}, 32.78$ $\mathrm{mmol})$ in THF $(3.6 \mathrm{ml})$ was introduced into the flask. To this mixture, $o$-bromostyrene $(4.00 \mathrm{~g}$, $21.85 \mathrm{mmol})$ in THF $(8.0 \mathrm{ml})$ was added dropwise for $1 \mathrm{~h}$, and the reaction mixture was stirred for further 2 days. After 2 days, the reaction mixture was poured into hexane, and the formed solid was removed by filtration. After evaporation of the solvent, the product, $o$-trimethylsilylstyrene in solution was separated and purified on column chromatography $(R f=0.53)$ in $58 \%$ yield.

Chemical shifts in ${ }^{1} \mathrm{H}$ NMR: 0.33 (s, 9H, $\left.-\mathrm{Si}\left(\mathrm{CH}_{3}\right)_{3}\right), 5.27\left(\mathrm{dd}, 1 \mathrm{H}, J_{2}=10.9 \mathrm{~Hz}, J_{2}=1.4\right.$ $\mathrm{Hz}, \mathrm{Hc}), 5.63\left(\mathrm{dd}, 1 \mathrm{H}, J_{1}=17.3 \mathrm{~Hz}, J_{2}=1.4 \mathrm{~Hz}\right.$, $\mathrm{Hb}), 7.07\left(\mathrm{dd}, 1 \mathrm{H}, J_{1}=17.3 \mathrm{~Hz}, J_{2}=10.9 \mathrm{~Hz}\right.$, $\mathrm{Ha})$, and $6.99-7.56 \mathrm{ppm}(\mathrm{m}, 4 \mathrm{H}$, aromatic).

$m$-Trimethylsilylstyrene $\left(m-S_{1}\right)$

Chemical shifts in ${ }^{1} \mathrm{H}$ NMR: 0.25 (s, 9H, $\left.-\mathrm{Si}\left(\mathrm{CH}_{3}\right)_{3}\right), 5.23\left(\mathrm{dd}, 1 \mathrm{H}, J_{1}=10.9 \mathrm{~Hz}, J_{2}=1.0\right.$ $\mathrm{Hz}, \mathrm{Hc}), 5.74\left(\mathrm{dd}, 1 \mathrm{H}, J_{1}=17.5 \mathrm{~Hz}, J_{2}=1.0 \mathrm{~Hz}\right.$, $\mathrm{Hb}), 6.72\left(\mathrm{dd}, 1 \mathrm{H}, J_{1}=17.5 \mathrm{~Hz}, J_{2}=10.9 \mathrm{~Hz}\right.$, $\mathrm{Ha})$, and 7.27-7.51 ppm (m, 4H, aromatic).

$p$-Trimethylsilylstyrene $\left(p-S_{1}\right)$

Synthesis and chemical shifts of this compound were already reported. ${ }^{1}$

\section{$o$-Pentamethyldisiloxanylstyrene $\left(\mathrm{o}-\mathrm{S}_{2}\right)$}

The Grignard reagent prepared from $o$ bromostyrene $(3.50 \mathrm{~g}, 19.12 \mathrm{mmol})$ and $\mathrm{Mg}$ turnings $(0.93 \mathrm{~g}, 38.24 \mathrm{mmol})$ in THF $(7.6 \mathrm{ml})$ was added dropwise to a solution of dimethyldichlorosilane $(4.60 \mathrm{ml}, 38.24 \mathrm{mmol})$ in THF $(4.3 \mathrm{ml})$ at room temperature, and allowed to react for $15 \mathrm{~h}$ at the temperature. After the reaction, the solution was concentrated to about one third in volume, dry hexane was added, and the formed solid was filtered under nitrogen atmosphere. The desired compound was purified by distillation, bp $35-40^{\circ} \mathrm{C} / 0.2 \mathrm{mmHg} .53 \%$ Yield.

To a solution of lithium trimethylsilanolate $(2.90 \mathrm{~g}, 30.17 \mathrm{mmol})$ in dry $\mathrm{THF}-\mathrm{Et}_{2} \mathrm{O}(1: 1 \mathrm{in}$ volume, $65 \mathrm{ml}$ ) was added dropwise dimethyl- chlorosilylstyrene $(5.37 \mathrm{~g}, 27.3 \mathrm{mmol})$ at room temperature, and the mixture was refluxed for further $10 \mathrm{~h}$. After the solvent was removed, hexane was added and the precipitated solid was removed by filtration. The product monomer was purified by column chromatography $(R f=0.48) .30 \%$ Yield.

Chemical shifts in ${ }^{1} \mathrm{H}$ NMR: $0.08(\mathrm{~s}, 9 \mathrm{H}$, $\left.-\mathrm{Si}\left(\mathrm{CH}_{3}\right)_{3}\right), 0.36,\left(\mathrm{~s}, 6 \mathrm{H},-\mathrm{Si}\left(\mathrm{CH}_{3}\right)_{2}\right), 5.24(\mathrm{dd}$, $\left.1 \mathrm{H}, J_{1}=10.9 \mathrm{~Hz}, J_{2}=1.4 \mathrm{~Hz}, \mathrm{Hc}\right), 5.64(\mathrm{dd}$, $\left.1 \mathrm{H}, J_{1}=17.3 \mathrm{~Hz}, J_{2}=1.4 \mathrm{~Hz}, \mathrm{Hb}\right), 7.15(\mathrm{dd}$, $\left.1 \mathrm{H}, J_{1}=17.3 \mathrm{~Hz}, J_{2}=10.9 \mathrm{~Hz}, \mathrm{Ha}\right), 7.08-7.59$ (m, $4 \mathrm{H}$, aromatic).

\section{$m$-Pentamethyldisiloxanylstyrene $\left(m-S_{2}\right)$}

Chemical shifts in ${ }^{1} \mathrm{H}$ NMR: $0.08(\mathrm{~s}, 9 \mathrm{H}$, $\left.-\mathrm{Si}\left(\mathrm{CH}_{3}\right)_{3}\right), 0.30\left(\mathrm{~s}, 6 \mathrm{H},-\mathrm{Si}\left(\mathrm{CH}_{3}\right)_{2}\right), 5.23(\mathrm{dd}$, $\left.1 \mathrm{H}, J_{1}=10.9 \mathrm{~Hz}, J_{2}=1.0 \mathrm{~Hz}, \mathrm{Hc}\right), 5.74(\mathrm{dd}$, $\left.1 \mathrm{H}, J_{1}=17.5 \mathrm{~Hz}, J_{2}=1.0 \mathrm{~Hz}, \mathrm{Hb}\right), 6.73(\mathrm{dd}$, $\left.1 \mathrm{H}, J_{1}=17.5 \mathrm{~Hz}, J_{2}=10.9 \mathrm{~Hz}, \mathrm{Ha}\right), 7.25-7.55$ (m, $4 \mathrm{H}$, aromatic).

$$
\text { p-Pentamethyldisiloxanylstyrene }\left(p-S_{2}\right)
$$

Synthesis and chemical shifts of this compound were already reported. ${ }^{1}$

\section{Polymerization}

Radical polymerization was carried out in solution at $60^{\circ} \mathrm{C}$ and $80^{\circ} \mathrm{C}$ using AIBN as the initiator under nitrogen atmosphere, as well as $\mathrm{K}_{2} \mathrm{~S}_{2} \mathrm{O}_{8}$ as the redox initiator. Anionic polymerization was also attempted.

\section{Purification of Polymers}

The polymers were dissolved in THF, poured into a large excess of methanol and allowed to coagulate. This procedure was repeated at least three times. Then benzene solution of the polymer was filtered and freeze-dried under vacuum.

\section{RESULTS AND DISCUSSION}

Comparison between polymerization under vacuum in sealed tube and under nitrogen atmosphere is shown in Table I. No important change was found in yield or in apparent molecular weight estimated by GPC. Accordingly 
Table I. Radical polymerization of monomers with AIBN at $60^{\circ} \mathrm{C}$

\begin{tabular}{|c|c|c|c|c|c|}
\hline \multirow{2}{*}{ Monomer } & \multirow{2}{*}{$\begin{array}{l}\text { Condi- } \\
\text { tion }\end{array}$} & Yield & \multirow{2}{*}{$\begin{array}{c}M_{w}{ }^{\mathrm{f}} \\
\times 10^{-4}\end{array}$} & \multirow{2}{*}{$\begin{array}{c}M_{n}^{\mathrm{f}} \\
\times 10^{-4}\end{array}$} & \multirow{2}{*}{$M_{w} / M_{n}^{\mathrm{f}}$} \\
\hline & & $\%$ & & & \\
\hline \multirow[t]{4}{*}{$o-\mathrm{S}_{1}$} & a & 3 & 1.1 & 0.8 & 1.4 \\
\hline & b & 5 & 0.9 & 0.7 & 1.3 \\
\hline & c & 6 & 1.0 & 0.7 & 1.4 \\
\hline & d & 5 & 0.9 & 0.7 & 1.3 \\
\hline$o-\mathrm{S}_{2}$ & $\mathrm{e}$ & 14 & 1.0 & 0.8 & 1.3 \\
\hline$m-\mathrm{S}_{1}$ & a & 41 & 34.6 & 20.4 & 1.7 \\
\hline$m-\mathrm{S}_{2}$ & e & 83 & 10.7 & 5.6 & 1.9 \\
\hline$p-\mathrm{S}_{1}$ & a & 54 & 45.3 & 23.6 & 1.9 \\
\hline$p-\mathrm{S}_{2}$ & a & 90 & 58 & 21.7 & 2.7 \\
\hline
\end{tabular}

a $0.1 \mathrm{~mol} \%$ Initiator in THF, in vacuum, $24 \mathrm{~h}$.

b $0.5 \mathrm{~mol} \%$ Initiator in THF, in $\mathrm{N}_{2}$ atm., $24 \mathrm{~h}$.

c $0.5 \mathrm{~mol} \%$ Initiator, bulk, in vacuum, $24 \mathrm{~h}$.

d $0.5 \mathrm{~mol} \%$ Initiator, bulk, in $\mathrm{N}_{2}$ atm., $24 \mathrm{~h}$.

e $0.7 \mathrm{~mol} \%$ Initiator in benzene, $24 \mathrm{~h}$.

f Estimated by GPC in THF correlating to standard polystyrene.

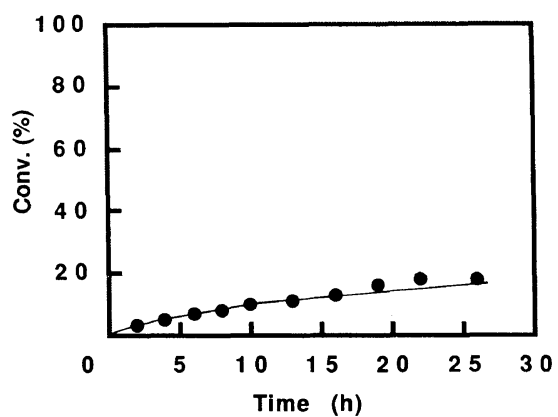

Figure 1. Time-conversion curve of the polymerization of $o$-S1 at $60^{\circ} \mathrm{C}$ in bulk with $0.5 \mathrm{~mol} \%$ AIBN under nitrogen atmosphere.

experiments were carried out either under vacuum or under nitrogen atmosphere.

Figure 1 shows time-conversion curve in the polymerization of $o-\mathrm{S}_{1}$ with $0.5 \mathrm{~mol} \%$ of AIBN in bulk. Although the polymerization rate is small, it can be seen that polymerization occurs. Typical GPC curves of the product are shown in Figure 2. The molecular weight of the polymer is considerably low compared with that of $m$-or $p$-isomers. It is also observed that poly $\left(o-\mathrm{S}_{1}\right)$ has relatively narrow molecular weight distribution $\left(M_{w} / M_{n} \sim 1.4\right)$. The poly-

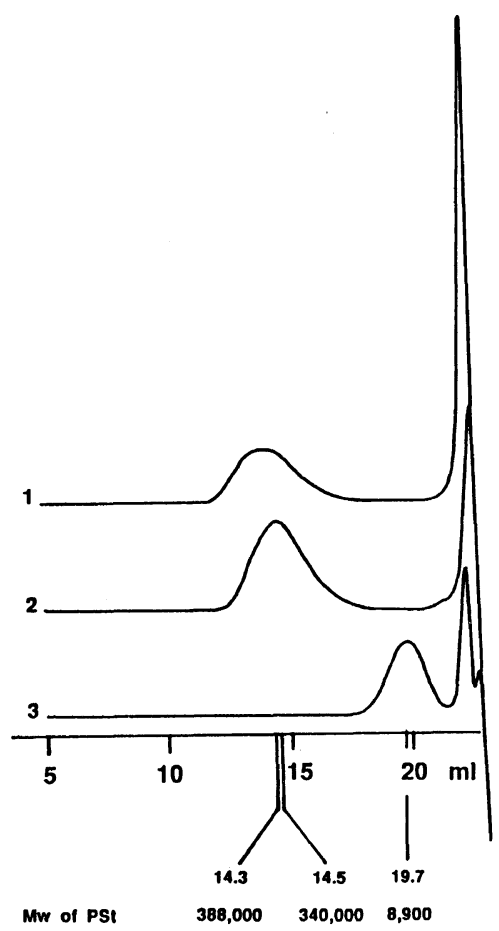

Figure 2. GPC chromatograms of: 1 , poly ( $p$-trimethylsilylstyrene); 2 : poly ( $m$-trimethylsilylstyrene); 3 , poly $(o-$ trimethylsilylstyrene). PSt, polystyrene.

dispersity of poly $\left(o-\mathrm{S}_{1}\right)$ slightly increased with polymerization time.

In emulsion polymerization at $50^{\circ} \mathrm{C}$, it was possible to obtain a considerably high molecular weight although the molecular weight distribution became a little wider. Generally, there is a trend that higher molecular weight can be obtained under the polymerization of lower temperature as shown in Table II.

The results of anionic polymerization are shown in Table III. We could observe the red color of living anion even under nitrogen atmosphere. Reasonably good agreement of number average molecular weights between GPC and VPO can be read in Table III. Accordingly, the molecular weight estimated by GPC was hereafter considered close to real value. Well-controlled molecular weight by the ratio of monomer to initiator and narrow molecular weight distribution of the polymer 
was attained in anionic polymerization.

Pogosyan et al. has reported the polymerizability of $o$-alkoxy substituted styrenes in radical polymerization. Against the behavior that can be expected, the bigger the $o$-substituent the higher the yields and molecular weights of the polymers. ${ }^{7}$ Methoxy, ethoxy, and propoxy substituted monomers showed not only low reactivity in the polymerization but also gave polymers of low intrinsic viscosity.

Our data observed in the polymerization of $o$-trimethylsilyl or $o$-pentamethyldisiloxanyl

Table II. Effect of temperature on polymerization behavior of $o$-substituted monomers

\begin{tabular}{cccccc}
\hline \multirow{2}{*}{ Monomer } & Temp & Yield & $\begin{array}{c}M_{w}{ }^{\mathrm{e}} \\
\times 10^{-4}\end{array}$ & $\begin{array}{c}M_{n}{ }^{\mathrm{e}} \\
\times 10^{-4}\end{array}$ & $M_{w} / M_{n}{ }^{\mathrm{e}}$ \\
\cline { 2 - 6 } & ${ }^{\circ} \mathrm{C}$ & $\%$ & & & \\
\hline$o-\mathrm{S}_{1}{ }^{\mathrm{a}}$ & 60 & 3 & 1.1 & 0.8 & 1.4 \\
$o-\mathrm{S}_{1}{ }^{\mathrm{a}}$ & 80 & 6 & 0.4 & 0.3 & 1.4 \\
$o-\mathrm{S}_{1}{ }^{\mathrm{b}}$ & 75 & 9 & 2.0 & 1.3 & 1.6 \\
$o-\mathrm{S}_{1}{ }^{\mathrm{d}}$ & 50 & 7.5 & 15 & 2.7 & 5.5 \\
$o-\mathrm{S}_{2}{ }^{\mathrm{d}}$ & 60 & 14 & 1.0 & 0.8 & 1.3 \\
$o-\mathrm{S}_{2}{ }^{\mathrm{d}}$ & 80 & 25 & 0.9 & 0.7 & 1.3 \\
\hline
\end{tabular}

a $0.1 \mathrm{~mol} \%$ AIBN in THF or benzene, $24 \mathrm{~h}$.

b $\mathrm{K}_{2} \mathrm{~S}_{2} \mathrm{O}_{8}, 0.5 \mathrm{wt} \% ; \mathrm{Na}_{2} \mathrm{HPO}_{4}, 0.5 \mathrm{wt} \%$; sodium lauryl sulfate, $2 \mathrm{wt} \% ; \mathrm{H}_{2} \mathrm{O}, 200 \mathrm{wt} \%, 7 \mathrm{~h}$.

c $\mathrm{K}_{2} \mathrm{~S}_{2} \mathrm{O}_{8}, 1 \mathrm{wt} \%$; $\mathrm{NaHPO}_{4}, 0.4 \mathrm{wt} \%$; sodium lauryl sulfate, $5 \mathrm{wt} \% ; \mathrm{H}_{2} \mathrm{O}, 200 \mathrm{wt} \%, 9 \mathrm{~h}$.

d $0.7 \mathrm{~mol} \%$ AIBN in benzene, $24-48 \mathrm{~h}$.

e Estimated by GPC in THF correlating to standard polystyrene.

Table III. Anionic polymerization ${ }^{\mathrm{a}}$ of $o-\mathrm{S}_{1}$ in $\mathrm{THF}$ at $-78^{\circ} \mathrm{C}$

\begin{tabular}{cccccc}
\hline \multirow{2}{*}{ Monomer } & \multicolumn{1}{c}{ Yield } & $\begin{array}{c}M_{w}^{\mathrm{b}} \\
\times 10^{-4}\end{array}$ & $\begin{array}{c}M_{n}{ }^{\mathrm{b}} \\
\times 10^{-4}\end{array}$ & $M_{w}{ }^{\mathrm{b}} / M_{n}$ & $M_{n, \mathrm{VPO}}{ }^{\mathrm{c}}$ \\
\hline$o-\mathrm{S}_{1}$ & 99 & 0.55 & 0.48 & 1.13 & 0.60
\end{tabular}

a Dry ice-acetone bath. $2 \mathrm{~mol} \%$ BuLi $(1.15 \mathrm{~N}$ in $n$-heptane) for $5 \mathrm{~h}$.

b Estimated by GPC in THF correlating to standard polystyrene.

c Determined by VPO. substituted styrenes were apparently similar to their data. Namely, only low molecular weight polymers could be obtained in low yield from the $o$-substituted monomers.

Chain transfer reaction by the abstraction of hydrogen atom of $\alpha$-carbon of alkoxy groups in monomer and already formed polymer seems to play an essential role in determining the yield and the molecular weight of the polymers in Pogosyan's results. Steric interaction of the substituent seems more important than the inductive effect in determining the relative rate between propagation and chain transfer reactions. Bulky substituents are advantageous to prevent chain transfer reaction by preventing the approach of the radical to hydrogen atom on $\alpha$-carbon.

In order to find the reason for such low molecular weight and low yield of the polymers in our research, chain transfer constant to monomer was estimated according to Mayo's simplified equation from the data of bulk polymerization in Figure 1.

$$
\frac{1}{D P}=C_{\mathrm{m}}+\frac{2 k_{\mathrm{td}}+k_{\mathrm{tc}}}{k_{\mathrm{p}}^{2}[\mathrm{M}]^{2}} R_{\mathrm{p}}=C_{\mathrm{m}}+\frac{2 k_{\mathrm{td}}+k_{\mathrm{tc}}}{k_{p}[\mathrm{M}]}\left[\mathrm{M}^{\circ}\right]
$$

$o$-Trimethylsilylstyrene showed considerably high $C_{\mathrm{m}}$ value $\left(120 \times 10^{-4}, 60^{\circ} \mathrm{C}\right)$ compared with other styrene type monomers. One order lower value was reported in the case of $p$-bromostyrene $\left(C_{\mathrm{m}}=23 \times 10^{-4}, 50^{\circ} \mathrm{C}\right)$ in which aromatic protons were activated to

Table IV. Fractional precipitation of $\operatorname{poly}\left(o-\mathrm{S}_{1}\right)^{\mathrm{a}}$ at $25^{\circ} \mathrm{C}$

\begin{tabular}{ccccc}
\hline Fraction & $\mathrm{MeOH} / \mathrm{FHT}$ & $\begin{array}{c}M_{w}{ }^{\mathrm{b}} \\
\times 10^{-4}\end{array}$ & $\begin{array}{c}M_{n}{ }^{\mathrm{b}} \\
\times 10^{-4}\end{array}$ & $M_{w} / M_{n}{ }^{\mathrm{b}}$ \\
\hline 1 & $1: 1$ & 1.2 & 1.0 & 1.2 \\
2 & $2: 1$ & 0.8 & 0.7 & 1.1 \\
3 & $5: 1$ & 0.24 & 0.22 & 1.1
\end{tabular}

a Prepared with $1 \mathrm{~mol} \%$ of AIBN in THF for 2 days.

b Estimated by GPC in THF correlating to standard polystyrene. 
permit chain transfer reaction by the presence of bromine atom. ${ }^{9}$ The trimethylsilyl group at the $o$-position may had some effect on the reactivity of the double bond of the monomer and also on the chain transfer reaction different from that of the alkoxy groups.

A possible explanation for such phenomena is degradative chain transfer to the monomer. This is probable since the polymerization rate (about $10^{-7} \mathrm{~mol} \mathrm{1}^{-1} \mathrm{~s}^{-1}$ ) decreased notably in comparison with the usual rate of styrene type monomers $\left(10^{-5} \mathrm{~mol} \mathrm{l}^{-1} \mathrm{~s}^{-1}\right)\left(k_{\mathrm{p}}\right.$ : in the order of $\left.10^{2} 1 \mathrm{~mol}^{-1} \mathrm{~s}^{-1}\right)^{9}$ and the values of DP estimated by GPC were also very small in the range of 25-50. Allyl acetate is a typical example of the degradative chain transfer $\left(C_{\mathrm{m}}=700 \times 10^{-4}, 80^{\circ} \mathrm{C}^{8}\right)$ with small DP $(\sim 14)$ and very low polymerization rate, in which the radical formed by chain transfer is greatly stabilized by resonance, and does not have the ability to reinitiate the polymerization. ${ }^{9}$

Fractional reprecipitation with $\mathrm{THF}$-methanol $(\mathrm{MeOH})$ at room temperature was made by changing the solvent composition on one of the samples prepared at $80^{\circ} \mathrm{C}$ with $1.0 \mathrm{~mol} \%$
AIBN for 2 days $(0.5 \mathrm{~mol} \%$ AIBN was added at the initial stage of the polymerization and after $24 \mathrm{~h}$ ). Changes in molecular weight estimated by GPC are shown in Table IV. The ${ }^{1} \mathrm{H}-\mathrm{NMR}$ spectrum, the crude polymer obtained from the polymerization mixture by precipitating into pure methanol showed a weak peak assignable to double bond near $5.2-5.3 \mathrm{ppm}$. This peak became further weaker in the repeatedly precipitated sample, and finally disappeared. This peak was not observed in any fractionated samples. On the other hand, this peak appeared strong in the sample recovered from the soluble part of fraction 3 as shown in Figure 3, though the absolute amount of the polymer was very little. The actual origin and the structure of the double bond were not elucidated.

Although some differences as the peak shape were noticed in GPC of each fraction with molecular weight between 2500 and 12000, the difference was not significant. In the IR spectrum of the polymer, an absorption of nitrile group assignable to a fragment from AIBN can be seen, specially in the low

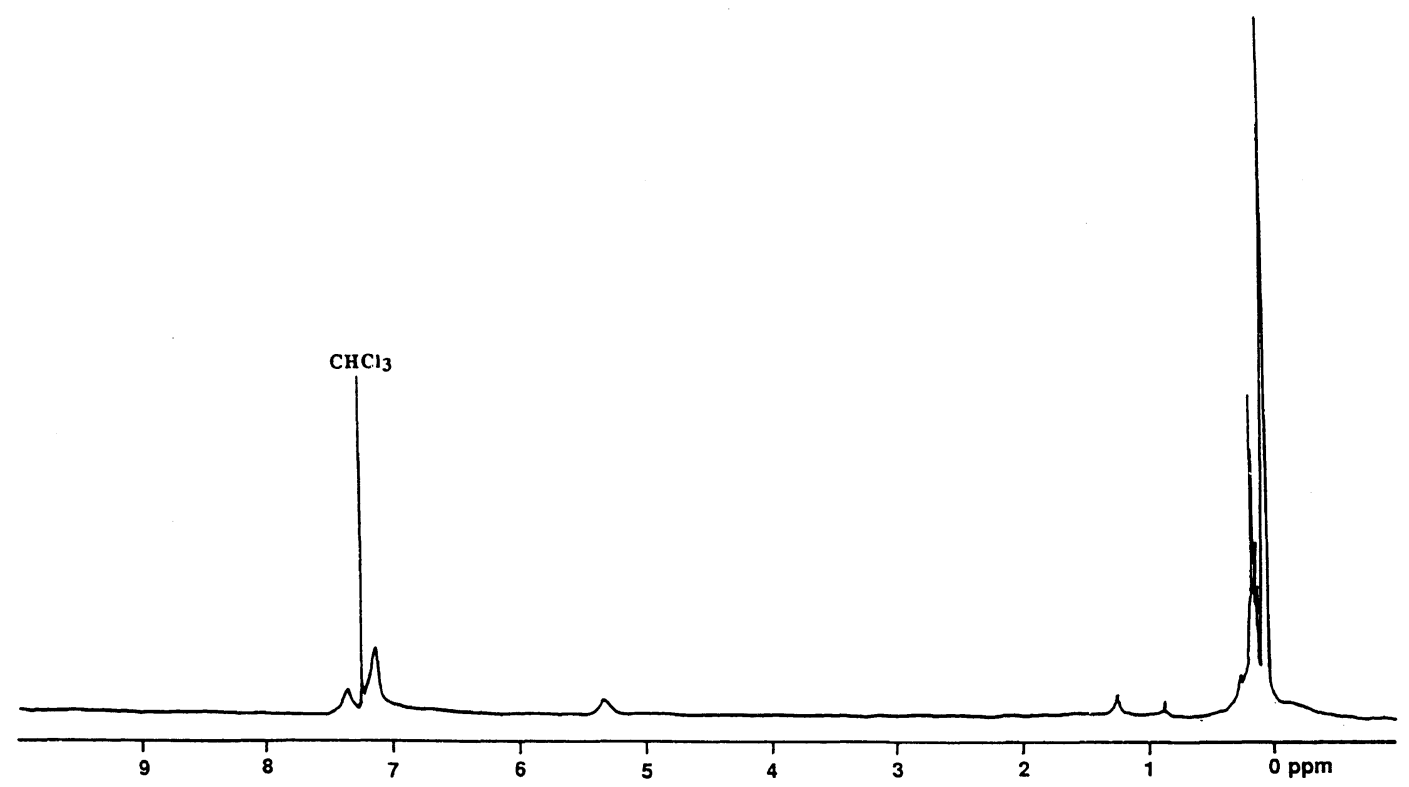

Figure 3. ${ }^{1} \mathrm{H}$ NMR spectrum of the soluble fraction in mixed solvent, THF: $\mathrm{MeOH}=1: 5(=$ soluble fraction of fraction 3 ). 
molecular weight sample. By taking into account that termination usually occurs by recombination in styrene type monomer, this suggests that the dead polymer is mainly formed by coupling of the propagating radicals and the chain transferred radical gives polymers of relatively lower molecular weight. The narrow molecular weight distribution of polymers (polydispersity of the polymers is less than or near to 1.5) is not at variance with this presumption.

For further understanding of the polymerizability of $o$-monomer, its structural features were studied in detail by ${ }^{1} \mathrm{H}$ NMR and ${ }^{13} \mathrm{C}$ NMR spectra. ${ }^{1} \mathrm{H}$ NMR spectra of these isomeric monomers are shown in Figure 4.

As can be seen from Figure 4, in $o-\mathrm{S}_{1}$, the Hc chemical shift does not change so much compared with that of $m$ - and $p$-isomers. Contrary to this, the $\mathrm{Hb}$ proton shifted to

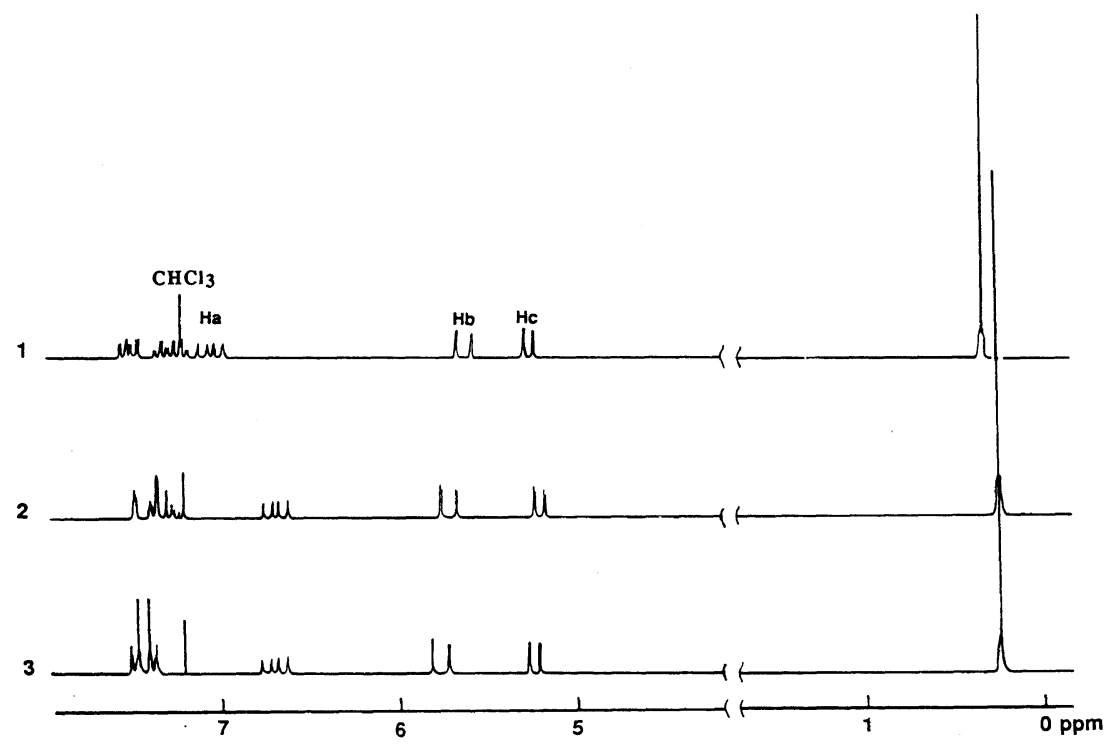

Figure 4. ${ }^{1} \mathrm{H}$ NMR spectra of isomerically trimethylsilyl substituted styrenes. $1, o-\mathrm{S}_{1} ; 2, m-\mathrm{S}_{1} ; 3, p-\mathrm{S}_{1}$.

Table V. NMR data on monomers

\begin{tabular}{|c|c|c|c|c|c|c|c|}
\hline \multirow{3}{*}{ Sample } & \multirow{3}{*}{$\frac{\text { Yield }}{\%}$} & \multicolumn{6}{|c|}{ Proton $^{\mathrm{a}}$ and carbon ${ }^{\mathrm{b}}$ chemical shift } \\
\hline & & \multicolumn{6}{|c|}{ ppm } \\
\hline & & $\mathrm{Ha}$ & $\mathrm{Hb}$ & $\mathrm{Hc}$ & $-\mathrm{Si}\left(\mathrm{CH}_{3}\right)_{3}$ & $-\mathrm{Si}\left(\mathrm{CH}_{3}\right)_{2}-$ & $-\mathrm{Si}\left(\underline{\mathrm{C}} \mathrm{H}_{3}\right)_{3}$ \\
\hline$o-\mathrm{S}_{1}$ & 66 & 7.07 & 5.63 & 5.27 & 0.33 & - & 0.15 \\
\hline$o-\mathrm{S}_{2}$ & 53 & 7.15 & 5.64 & 5.24 & 0.08 & 0.36 & \\
\hline$m-\mathrm{S}_{1}$ & 79 & 6.72 & 5.74 & 5.23 & 0.25 & - & 1.45 \\
\hline$m-\mathrm{S}_{2}$ & 67 & 6.73 & 5.74 & 5.23 & 0.08 & 0.30 & \\
\hline$p-\mathrm{S}_{1}$ & 82 & 6.70 & 5.76 & 5.24 & 0.25 & - & 1.43 \\
\hline$p-\mathrm{S}_{2}$ & 90 & 6.71 & 5.77 & 5.24 & 0.08 & 0.29 & \\
\hline
\end{tabular}

a $200 \mathrm{MHz}{ }^{1} \mathrm{H} \mathrm{NMR}$ in $\mathrm{CDCl}_{3}$.

b $50 \mathrm{MHz}{ }^{13} \mathrm{C} \mathrm{NMR}$ in $\mathrm{CDCl}_{3}$. 
higher field, while $\mathrm{Ha}$ and trimethylsilyl proton were rather deshielded. Trimethylsilyl carbon of $o$-isomer is found at a considerably shielded position $(0.15 \mathrm{ppm})$ compared with $m$ - and $p$-isomers (1.45 and $1.43 \mathrm{ppm}$, respectively). The chemical shifts of monomers are tabulated in Table $\mathrm{V}$.

Such shifts in NMR spectra can be reasonably understood by considering the effect of the bulky trimethylsilyl group approaching the Ha proton. Under such circumstances, van der Waals intramolecular interaction between trimethylsilyl group and $\mathrm{Ha}$ proton becomes important. London dispersion force increases and the chemical shifts of both trimethylsilyl and $\mathrm{Ha}$ protons go to lower fields. ${ }^{10}$ On the other hand, the steric hindrance between the trimethylsilyl group and $\mathrm{Ha}$ proton forces the benzene ring and double bond to be slightly twisted, and as a consequence, results in partial loss of coplanarity. From this point of view, the $\mathrm{Ha}$ and trimethylsily protons must shift to higher fields as the $\mathrm{Hb}$ proton does. As the $\mathrm{Ha}$ and trimethylsilyl methyl prontons are actually deshielded, it can be concluded that here the van der Waals effect is more important than the effects of the loss of coplanarity.

The close location of trimethylsilyl group and $\mathrm{Ha}$ proton causes a slight twisting of bonding between trimethylsilyl carbon and benzene ring. This twisting causes a compression effect on carbons, and makes them shift to higher field in ${ }^{13} \mathrm{C}$ NMR. ${ }^{11}$

In order to estimate the proximity between trimethylsilyl group and $\mathrm{Ha}$ proton, NOE and trimethylsilyl carbon relaxation times were measured as shown in Table VI.

The relaxation time of trimethylsilyl carbon of $o-\mathrm{S}_{1}$ is shorter than those of $m$ - and $p$-isomers. This suggests that a longer contact of trimethylsilyl group with $\mathrm{Ha}$ which eases the relaxation through proton-carbon spin exchange. Of course, the rotation of trimethylsilyl group is not completely restricted by the presence of $\mathrm{Ha}$, so the difference in the relaxation time in comparison with $m$ - and
Table VI. Carbon spin-lattice relaxation time ${ }^{\mathrm{a}}$ of $\mathrm{SiCH}_{3}$ and proton $\mathrm{NOE}^{\mathrm{b}}$

\begin{tabular}{|c|c|c|c|}
\hline \multirow{2}{*}{ Sample } & $T_{1}$ & \multirow{2}{*}{$\begin{array}{l}\mathrm{NOE} \\
\text { at } \mathrm{Ha}\end{array}$} & \multirow{2}{*}{$\begin{array}{l}\mathrm{NOE} \\
\text { at } \mathrm{Hm}^{\circ}\end{array}$} \\
\hline & $\mathrm{s}$ & & \\
\hline$o-\mathrm{S}_{1}$ & 5.6 & 1.09 & 1.07 \\
\hline$m-\mathrm{S}_{1}$ & 6.1 & - & - \\
\hline$p-\mathrm{S}_{1}$ & 5.9 & - & - \\
\hline
\end{tabular}

a Estimated by $50 \mathrm{MHz}{ }^{13} \mathrm{C} \mathrm{NMR}$ in $\mathrm{CDCl}_{3}$.

b Estimated by $500 \mathrm{MHz}$ by ${ }^{1} \mathrm{H}$ NMR by irradiating on trimethylsilyl proton.

c See the text.

Table VII. IR data on monomers

\begin{tabular}{|c|c|c|}
\hline Sample & $\begin{array}{c}\mathrm{C}=\mathrm{C}^{\mathrm{a}} \\
v\end{array}$ & $\begin{array}{c}\mathrm{Si}\left(\mathrm{CH}_{3}\right)_{2}{ }^{\mathrm{a}} \\
\delta_{\mathrm{as}}\end{array}$ \\
\hline$o-\mathrm{S}_{1}$ & 1626 & 1415 \\
\hline$o-\mathrm{S}_{2}$ & 1628 & 1412 \\
\hline$m-\mathrm{S}_{1}$ & 1632 & 1381 \\
\hline$m-\mathrm{S}_{2}$ & 1632 & 1381 \\
\hline$p-\mathrm{S}_{1}$ & 1630 & 1392 \\
\hline$p-\mathrm{S}_{2}$ & 1630 & 1392 \\
\hline
\end{tabular}

a $v$, stretching vibration; $\delta$, bending vibration wavenumber in $\mathrm{cm}^{-1}$.

$p$-isomers is not remarkable.

Although an interaction between $\mathrm{Ha}$ and trimethylsilyl proton is also observed in the NOESY spectrum, a definitive conclusion cannot be presented owing to the low signal noise ratio. In NOE spectrum under irradiation at trimethylsilyl proton, $\mathrm{Ha}$ shows $\mathrm{NOE}$ of 1.09. NOE at $m$-aromatic proton $(o-$ to trimethylsilyl group, $\mathrm{Hm}$ ) is also determined to be 1.07 .

In IR, the $\mathrm{C}=\mathrm{C}$ stretching vibration shifts to lower frequency in comparison with $m$ - and $p$-isomers. This is due to the partial loss of coplanarity which makes $\mathrm{C}=\mathrm{C}$ bond weaker. It is also suggested that $\mathrm{Si}\left(\mathrm{CH}_{3}\right)_{3}$ interacts with the Ha proton, since $\mathrm{Si}-\mathrm{C}$ asymmetric bending vibration of $\mathrm{Si}\left(\mathrm{CH}_{3}\right)_{2}$ appears at higher frequency. The wavenumbers are shown in Table VII. 
From the data mentioned above, it can be said that in $o$-trimethylsilylstyrene, trimethylsilyl and Ha protons interact enough to produce a partial loss of the coplanarity of the $\pi$-system between the benzene ring and vinyl group.

Steric interaction between the trimethylsilyl group and $\mathrm{Ha}$ proton gives a marked influence on polymerization behavior. In the course of polymerization, the bulky trimethylsilyl group causes a severe steric hindrance for the monomer and propagating radical when they approach. However, once a double bond is opened, the formed propagating radical is stabilized by release of strain energy, and more importantly probably by the participation of the empty $d$-orbital on silicon atom present close to the radical $p$-orbital. This would make the propagation slow.

The molecular weight of the polymer in bulk polymerization is mainly determined by termination and transfer reactions. It would be reasonable to rewrite eq 1 to eq 2 in the case of styrene derivatives.

$$
\frac{1}{D P}=C_{\mathrm{m}}+\frac{k_{\mathrm{tc}}}{k_{\mathrm{p}}[\mathrm{M}]}[\mathrm{M}]
$$

From the discussion above, the reason for low molecular weight of polymers seems to be brought about by small $k_{\mathrm{p}}$, and large $k_{\mathrm{tc}}$ and $C_{\mathrm{m}}$. Especially, the rate of chain transfer reaction seems a controlling factor determining the molecular weight of the polymer. Tentative postulation for the stabilization of radicals by empty $d$-orbital on silicon is shown in Scheme 2 .

The propagating radical might be stabilized by the empty $d$-orbital on silicon atom (Scheme $2-1)$. The propagating radical may be in equilibrium with silylmethyl radical via intramolecular hydrogen shift. Such stabilization would result in slow propagation. Stabilization of the chain transfered radical, probably on trimethylsilyl group or on aromatic ring, is also an important factor. Stabilization of adjacent carbon radical by the empty $d$-orbital on silicon atom (Scheme 2-2) in the case of phenyldimethylsilylmethyl radical and aromatic radical at $o$-position to trimethylsilyl group is quite plausible. ${ }^{12}$ At present, we consider the structure of the right side is more reasonable. Such a chain transfered radical, especially the phenyldimethylsilylmethyl radical, would easily combine to produce low molecular weight compounds which retain double bonds, or intramolecularly add to the double bond to form a reinitiating radical which does not have double bonds as shown

1
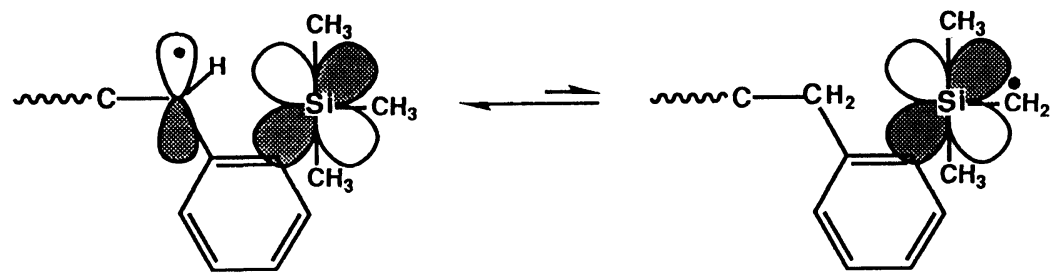

2
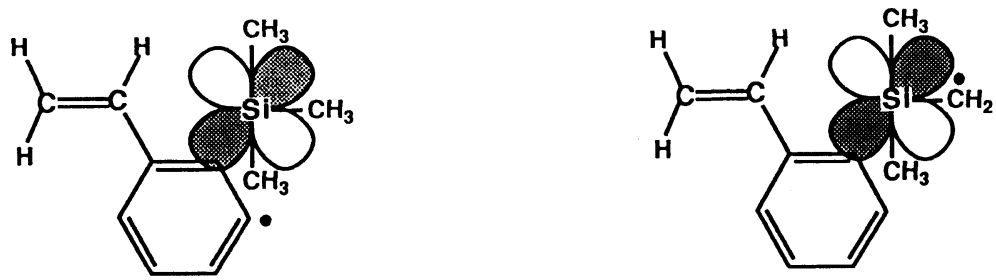

Scheme 2. Tentative postulation for the stabilization of radicals by empty $d$-orbital on silicon atom. 

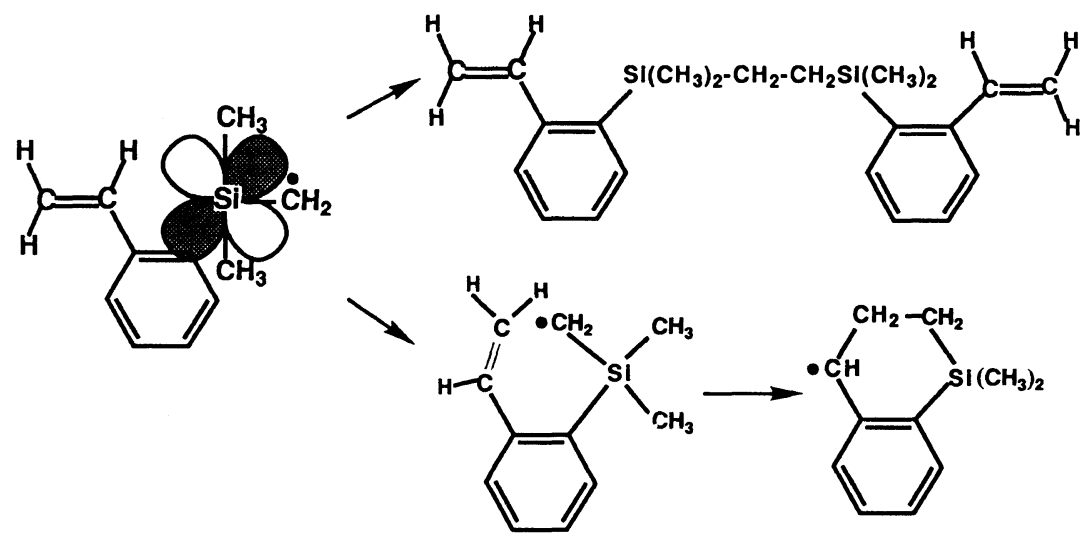

Scheme 3. Intramolecular addition of chain transferred radical to the double bond of the molecule.

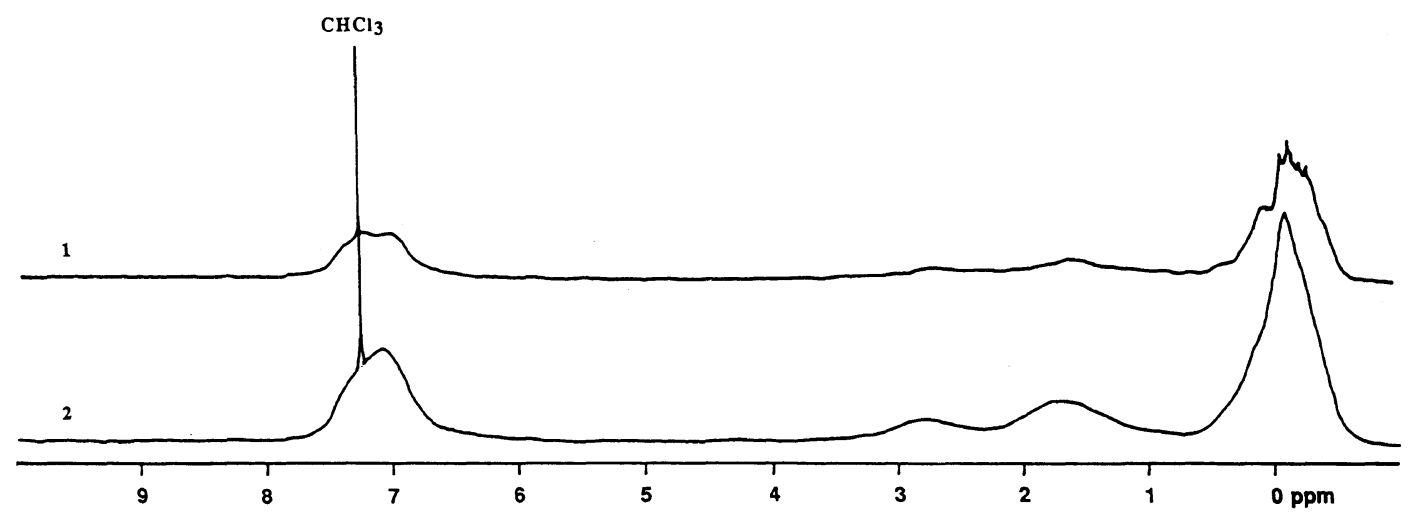

Figure 5. ${ }^{1} \mathrm{H}$ NMR spectra of poly $\left(o-\mathrm{S}_{1}\right)$ prepared by 1 , anionic and 2, radical polymerizations.

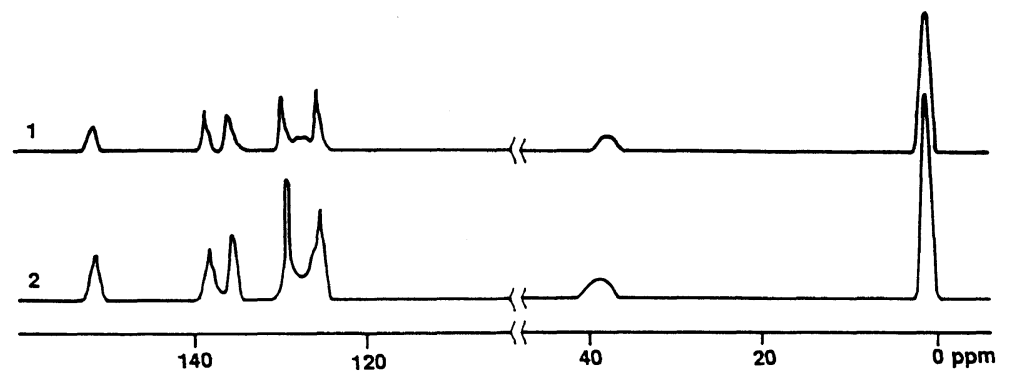

Figure 6. ${ }^{13} \mathrm{C}$ NMR spectra of poly $\left(o-\mathrm{S}_{1}\right)$ prepared by 1 , anionic and 2, radical polymerizations.

in Scheme 3. Since only small amounts of double bonds were observed in polymer, the latter mechanism is plausible.

We can say that the formation of stable radicals in propagation and chain transfer reactions by empty $d$-orbital on silicon atom seems to give a situation which resembles degradative transfer to monomer with slow propagation and fast termination, and results in the characteristics of the low monomer conversion and low molecular weight of the obtained polymer. In anionic polymerization, 
chain transfer reaction apparently does not occur. The stabilization of an anion on the $\alpha$-carbon is also helped by the presence of empty $d$-orbital on silicon atom at the $o$ position.

Typical ${ }^{1} \mathrm{H}$ NMR and ${ }^{13} \mathrm{C}$ NMR spectra of the polymers are shown in Figures 5 and 6 . In the ${ }^{1} \mathrm{H}$ NMR spectrum, in the region close to $0 \mathrm{ppm}$ appears a wide peak which undoubtedly assignable to the $\mathrm{Si}\left(\mathrm{CH}_{3}\right)_{3}$ of the repeating units. The broadness of the peak may reflect the very low mobility of this units in the polymer or the wide variety in tacticity or both.

There is not much difference in the ${ }^{13} \mathrm{C}$ NMR spectra. The signals at around 1.6 and $39 \mathrm{ppm}$ can be assigned to methyl carbons of trimethylsilyl group, and methine and methylene carbons in polystyrene main chain. The signals at 125-128, 129,136, 138, and $151 \mathrm{ppm}$ are assignable to $\mathrm{C} 4$ and $\mathrm{C} 5, \mathrm{C} 6, \mathrm{C} 3, \mathrm{C} 1$, and $\mathrm{C} 2$, respectively. This suggests that the polymers obtained by radical polymerization principally have the vinyl-polymerized structure. Termination reaction by coupling of

Table VIII. Molecular weights and glass transition temperatures of the polymers

\begin{tabular}{lcccc}
\hline Sample & $\begin{array}{c}M_{w}{ }^{\mathrm{e}} \\
\times 10^{-4}\end{array}$ & $\begin{array}{c}M_{n}{ }^{\mathrm{e}} \\
\times 10^{-4}\end{array}$ & $M_{w} / M_{n}{ }^{\mathrm{e}}$ & $T_{\mathrm{g}}$ \\
\hline Poly $\left(o-\mathrm{S}_{1}\right)^{\mathrm{a}}$ & 28 & 16 & 1.8 & 175 \\
Poly $\left(o-\mathrm{S}_{1}\right)^{\mathrm{b}}$ & 0.55 & 0.48 & 1.13 & 155 \\
$\operatorname{Poly}\left(o-\mathrm{S}_{2}\right)^{\mathrm{c}}$ & 1.0 & 0.8 & 1.3 & 114 \\
& & & & \\
$\operatorname{Poly}\left(m-\mathrm{S}_{1}\right)^{\mathrm{d}}$ & 34.6 & 20.4 & 1.7 & 66 \\
$\operatorname{Poly}\left(m-\mathrm{S}_{2}\right)^{\mathrm{c}}$ & 10.7 & 5.6 & 1.9 & -14 \\
& & & & \\
$\operatorname{Poly}\left(p-\mathrm{S}_{1}\right)^{\mathrm{d}}$ & 45.3 & 23.6 & 1.9 & 136 \\
$\operatorname{Poly}\left(p-\mathrm{S}_{2}\right)^{\mathrm{d}}$ & 58 & 21.7 & 2.7 & 36 \\
\hline
\end{tabular}

${ }^{\text {a }} \mathrm{K}_{2} \mathrm{~S}_{2} \mathrm{O}_{8}, 1 \mathrm{wt} \% ; \mathrm{Na}_{2} \mathrm{HPO}_{4}, 0.4 \mathrm{wt} \%$; sodium lauryl sulfate, $5 \mathrm{wt} \% ; \mathrm{H}_{2} \mathrm{O}, 200 \mathrm{wt} \%, 9 \mathrm{~h}$.

b $2 \mathrm{~mol} \% \mathrm{BuLi}\left(1.15 \mathrm{~N}\right.$ in $n$-hepatane) in THF at $-78^{\circ} \mathrm{C}$ for $5 \mathrm{~h}$.

c $0.7 \mathrm{~mol} \%$ AIBN in benzene, $24 \mathrm{~h}$.

d $0.1 \mathrm{~mol} \%$ AIBN in THF or benzene, $24 \mathrm{~h}$.

e Estimated by GPC in THF correlating to standard polystyrene.

f Measured by DSC at a heating rate $10^{\circ} \mathrm{C} \mathrm{min}^{-1}$. stabilized propagation radical by silicon atom seems to mainly determine the molecular weight of the polymer in radical polymerization. Methyl groups on $\alpha$ silicon atom of $p$-pentamethyldisiloxanylstyrene seem to act similarly with the trimethylsilyl group.

Higher temperature probably allows the propagating radicals more quickly to terminate and results in lower molecular weight of the polymer.

Glass transition temperatures of polymer are shown in Table VIII.

The effect of the substituent on glass transition temperature mainly depends at which position it is attached and if it contains siloxane linkages or not. When bulky trimethylsilyl groups are attached to the aromatic ring, glass transition temperatures become higher. This is most notable at $o$-position. By the introduction of siloxane linkage in the substituent, the glass transition temperature drops sharply. The decrease in glass transition temperature of polystyrene with $o$-pentamethylsiloxanyl substituents is minimal among disiloxanyl substituted polymers.

Further study is now in progress to elucidate the structures of polymers, and obtain more insight into the reaction mechanism.

Acknowledgments. Financial supports from a Grant-in-Aid for Scientific Research on Priority Areas, New Functionality MaterialsDesign, Preparation and Control (02205057) and from a Grant-in-Aid for Developmental Scientific Research (63850184) are gratefully acknowledged.

\section{REFERENCES}

1. Y. Kawakami, T. Aoki, H. Hisada, Y. Yamamura, and Y. Yamashita, Polym. Commun., 26, 133 (1985).

2. Y. Kawakami, H. Karasawa, T. Aoki, Y. Yamamura, H. Hisada, and Y. Yamashita, Polym. J., 17, 1159 (1985).

3. Y. Kawakami, H. Karasawa, H. Kamiya, T. Aoki, and Y. Yamashita, Polym. J., 18, 237 (1986).

4. Y. Kawakami, T. Sugisaka, and Y. Yamashita, Polym. J., 20, 685 (1988). 
5. Y. Kawakami and T. Sugisaka, J. Membrane Sci., 50, 189 (1990).

6. W. Takagi, I. Inoue, Y. Yano, and T. Okonogi, Tetrahedron Lett., 2587 (1974).

7. G. M. Pogosyan, L. M. Akopyan, E. V. Vanyan, and S. G. Matsoyan, Vysokomol. Soedin Ser., B, 13, 242 (1971).

8. J. Brandrup and E. H. Immergut, "Polymer Handbook," third ed, Wiley Interscience, New York, N.Y., 1989.

9. G. Odian, "Principles of Polymerization," John Wiley
\& Sons, New York, N.Y., 1981, p 250.

10. L. M. Jackman and S. Sternhell, "Application of Nuclear Magnetic Resonance Spectroscopy in Organic Chemistry," Pergamon Press, New York, N.Y., 1969, p 71.

11. E. Breitmaier and W. Voelter, "Carbon-13 NMR Spectroscopy," VCH Publishers, Weinheim, Germany, 1987, p 115.

12. E. Colvin, "Silicon in Organic Synthesis," Butterworth and Co., London, 1981, p 10. 